Yew Wong, Chee and Acur, Nuran (2010) Understanding inter-organizational decision coordination. Supply Chain Management: An International Journal . ISSN 1359-8546

http://strathprints.strath.ac.uk/13761/

This is an author produced version of a paper published in Supply Chain Management: An International Journal . ISSN 1359-8546.

Strathprints is designed to allow users to access the research output of the University of Strathclyde. Copyright (C) and Moral Rights for the papers on this site are retained by the individual authors and/or other copyright owners. You may not engage in further distribution of the material for any profitmaking activities or any commercial gain. You may freely distribute both the url (http://strathprints.strath.ac.uk) and the content of this paper for research or study, educational, or not-for-profit purposes without prior permission or charge. You may freely distribute the url (http://strathprints.strath.ac.uk) of the Strathprints website.

Any correspondence concerning this service should be sent to The Strathprints Administrator: eprints@cis.strath.ac.uk 
Revised manuscript submitted to SCM:AIJ Special Issue on Decision Making and Analysis within Supply Chains dd. 2-March-2009

\title{
Understanding Inter-Organizational Decision Coordination
}

\begin{abstract}
Purpose: This article develops a theoretical framework to investigate the interaction and coordination of decision-making processes in a supply chain with multiple and inter-dependent suppliers and customers.

Design/Methodology/Approach: Three longitudinal case studies on the decision coordination processes between a European toy supplier and three retailers.

Findings: The case studies found different mental models, decision-making behaviours, coordination behaviours and ordering behaviours even though the toy supplier and the three retailers observed quite the same material flow behaviours. The study found explanations for these diverse behaviours by analyzing the mental models and decision-making behaviours of each involved party.

Originality/value: The findings explain the conditions which lead to undesirable mental models and decision-making behaviours which affect the coordination of decisions among supply chain members.
\end{abstract}

Keywords: Decision-making, inter-organizational coordination, case study, toy industry.

Article type: Case study 
Revised manuscript submitted to SCM:AIJ Special Issue on Decision Making and Analysis within Supply Chains dd. 2-March-2009

\section{Introduction}

A supply chain is fully coordinated when all decisions for accomplishing global system objectives are aligned (Sahin and Robinson, 2002). Particularly, ordering decisions of supply chain members have to be coordinated so that the rate of order fulfilment is synchronized with the rate of consumption at the lowest possible cost (Dyer and Singh, 1998; Simatupang et al., 2002). Despite the importance of interorganizational decision coordination, much of the logistics and supply chain literature (e.g. Thomas and Griffin, 1996; Metters, 1997; Lewis and Talalayevsky, 2004) seldom considers the influence of inter-organizational decision coordination on material (physical) flows (Malone and Crowston, 1994). Another problem is that the literature often assumes that decision-makers are rational, competent and consistent in making decisions. In reality no decision-maker can be completely rational (Simon, 1978). In a complex environment they may lack cognitive capacity to understand the consequences of a particular decision (Heiner, 1983; Senge, 1990). Shortage gaming behaviour is a perfect example of such a rationally limited and inconsistent decision behaviour, it occurs when supply chain members make decisions independently without coordination with each other (Lee et al., 1997).

Recognising the above literature gap, many scholars have called for an alternate research approach to understand the coordination of decisions in a multiechelon supply chain (Clark and Scarf, 1960; Silver, 1981; Heiner, 1983; Sahin and Robinson, 2002; Hopp, 2004; Knoppen and Christiaanse, 2007). Since different members of a supply chain hold different mental models and act accordingly (Akkermans et al., 1999), it is imperative to understand the roles of mental models, decision behaviours and coordination behaviours (Dyer and Singh, 1998; Lane and Lubatkin, 1998; Boddy et al., 2000; Knoppen and Christiaanse, 2007). If the logics 
Revised manuscript submitted to SCM:AIJ Special Issue on Decision Making and Analysis within Supply Chains dd. 2-March-2009

behind decisions are not well understood (Senge, 1990), it is difficult to generate novel managerial recommendation and advance the theory of supply chain coordination. Therefore, the central question to be addressed by this article is - "how to develop an alternative research approach which explains inter-organizational decision coordination behaviour in reality?"

In search of such an alternative approach, this article develops a theoretical framework which aims at understanding the coordination of decision-making processes among multiple and inter-dependent suppliers and customers in a supply chain network. We combine relevant theories from the logistics and supply chain literature and the decision-making literature as the building blocks of the theoretical framework. The framework is then used to guide the collection of data from a longitudinal case study between a toy supplier and three of its European retailers. The case analyses provide rich descriptions of the interactions between decision behaviour, coordination behaviour and ordering behaviour and further provide better explanations of the logics (mental models) of the involved decision-makers. Such explanations further lead to several novel recommendations for supply chain managers to manage the complexity of decision-making coordination in a supply chain. In terms of theoretical contribution, the article extends the knowledge of supply chain coordination by identifying various mental models and decision-making coordination behaviours and linking them to explain various ordering behaviours, coordination behaviours and physical flow behaviours.

\section{Theoretical framework}

Combining logistics and supply chain literature and decision-making literature, this section develops a theoretical framework to understand coordination of decisionmaking processes in a supply chain network. Section 2.1 establishes the main 
Revised manuscript submitted to SCM:AIJ Special Issue on Decision Making and Analysis within Supply Chains dd. 2-March-2009

constructs and their measures. They are used to develop the theoretical framework of inter-organizational decision coordination in section 2.2.

\subsection{Theoretical constructs and their measures}

Figure 1 illustrates the main theoretical constructs (and their measures) necessary to develop a theoretical framework of inter-organizational decision coordination. Based on the logistics and supply chain literature we have included three constructs: flow (physical) behaviour, ordering behaviour and coordination behaviour. From the decision-making literature we have incorporated two constructs: decision-making behaviour and mental model. The meanings of these five constructs and their relevant measures are established in the following sub-sections.

$<<$ Please insert figure 1 around here $>>$

\subsubsection{Mental Model}

We have chosen to include mental model into the framework because it is the ultimate source of the knowledge, decision and action in a supply chain (Hopp, 2004). Barr et al. (1992) defined individual mental model as the consistence of concepts and relationships an individual uses to understand various situations or environments. The environments we refer to in this article are the physical flows (flow behaviours) and order behaviour of other supply chain members. At the organizational level, mental model is defined as the framework of organizational rationalities and belief systems on which formal analyses, policies and procedure are based (Hill and Levenhagen, 1995). Mental model often defines what is important and unimportant for an organization (Kiesler and Sproull, 1982). 
Revised manuscript submitted to SCM:AIJ Special Issue on Decision Making and Analysis within Supply Chains dd. 2-March-2009

Basically, mental model helps individuals to make sense of their reasoning regarding their observations of the environment. Broadly, individuals make sense of their reasoning with either a rational (analytic) or a generative (intuitive) approach (Allison and Hayes, 1996). Table I summarizes the main measures of these two mental models. In terms of thinking nature and thinking guide, rational reasoning tends to be more compliant, favours a deductive and structured approach to problemsolving, and depends on systematic methods or formal rules of investigation (Allison and Hayes, 1996). Instead, generative reasoning tends to be intuitive, prefers an openended approach to problem-solving and creativity, and relies on random methods of exploration and informal rules (Allison and Hayes, 1996).

$<<$ Please insert table I around here $>>$

The choice of reasoning approaches is usually dependent on the decision-makers' knowledge of the cause and effect between a particular decision and the subsequent outcome (Hodgkinson et al., 1999; Bogner and Barr, 2000; Kurtz and Snowden, 2003). When cause and effect is "known", organizations usually react with "sensecategorize-respond" using standard operating procedure and legitimate best practice. When case and effect is "knowable" or separated over time, organizations usually react with "sense-analyze-respond" such as the use of scenario planning and systems thinking (Kurtz and Snowden, 2003). These two sense-making traits are typically applied in an analytical reasoning.

However, in most practical situations, generative (intuitive) reasoning governs organizational mental models. Even though we often believe that we learn best from experience, the problem is that decision-makers in a complex environment are unable 
Revised manuscript submitted to SCM:AIJ Special Issue on Decision Making and Analysis within Supply Chains dd. 2-March-2009

to learn directly from experiencing the consequences of their decisions (Senge, 1990). In a complex environment, when cause and effect are only coherent in retrospect and do not repeat, organizations often "probe-sense-respond" using pattern management, perspective filters, or complex adaptive systems (Surana et al., 2005; Pathak et al., 2007). Furthermore, in a chaotic environment without knowledge of the cause and effect relationship, organizations may "act-sense-respond" with stability-focused intervention, enactment tools, or even crisis management (Kurtz and Snowden, 2003). These two sense-making traits fall under the generative (intuitive) reasoning mental models (Sadler-Smith, 2004).

In summary, Table I provide us with appropriate measures to identify mental models of decision-makers, either being rational (analytic) or generative (intuitive). Despite critique by Skinner (1978) that it is "impossible" to collect reliable data about someone's mental model, we believe that the measures specified in Table I make it reasonably achievable (Knight et al., 1999).

\subsubsection{Decision Behaviour}

Mental model, whether being analytic or intuitive, will influence the decision-making process (March and Olsen, 1975; Day and Lord, 1992). Decision-making concerns making choices between alternatives (Raiffa, 1968). According to decision-making literature, "what to decide" (the goal or the problem definition) and "how to decide" (the decision-making process and the criteria of a good decision) are the two essential measures of decision-making behaviour. When deciding "what to decide", decisionmakers often attribute root causes to their problems and then set goals. Attribution theory suggests that individuals often assign four root causes (e.g. ability, effort, task difficulty, and luck) when evaluating performance (Weiner, 1972; Kelly, 1973). Decision-makers may attribute poor performance using internal attribution (e.g. 
Revised manuscript submitted to SCM:AIJ Special Issue on Decision Making and Analysis within Supply Chains dd. 2-March-2009

ability and effort), external attribution (e.g. environmental factors such as task difficulty and luck), stable attribution (factors that are unchanged over time), or unstable attribution (factors that are variable over time, for example effort and luck). Since attribution behaviour can affect goal setting, it is considered an essential measure of decision behaviour.

When deciding "how to decide", decision-makers define criteria for a "good" decision. Such criteria may vary according to the extent of available information, cognitive capability, and risk-taking behaviour during the decision-making process. Baird (1989) suggests that decision-makers exhibit different risk-taking attitudes in different decision situations i.e. decision under certainty (or at least calculable risk) and decision under complex or chaotic environments. There are typically four risktaking attitudes (Baird, 1989), which represents another essential measure of decisionmaking behaviour:

- The supremely optimistic decision-makers, who use maximal criterion (the best possible gain) for the chosen option. They are usually the risk-loving decision-makers (Friedman and Savage, 1948; Arrow, 1951);

- The supremely pessimistic decision-makers, who use minimal criterion (the lowest worst that can be) for the chosen option. They are usually the riskaverse decision-makers (Friedman and Savage, 1948; Arrow, 1951);

- The equally-likely-criteria decision-makers, who use the famous principle of insufficient reason (considered as the most rational behaviour) that "if you know of no reason for one state of nature to be more likely than the other, you must treat them as being equally likely";

- The decision-makers who decide based on "regret as a measure of opportunity loss". They try to choose an option which provides the least possible loss. 


\section{Revised manuscript submitted to SCM:AIJ Special Issue on Decision Making and Analysis within Supply Chains dd. 2-March-2009}

The above decision-making behaviours can be revealed by interviewing decisionmakers about the decisions they made in response to observed flow behaviour. Further discussion with the decision-makers will help to reveal the mental models which governed their decision-making behaviours.

\subsubsection{Coordination Behaviour}

During a decision-making process, decision-makers may realize the need for coordinating their decisions with some supply chain members. For example, when decision-makers attribute the causes of a poor material flow externally to their supply chain members, there is a need to coordinate decisions. Since no organization is likely to offer their formal decision authority to another independent organization, they must then engage in persuasion, negotiation, exchange of information and adjustment to achieve their common goals (Scott, 1961). Inter-organizational decision coordination is likely to take place when organizations begin to consider other organizations in their decision-making process.

Since decision coordination behaviours may vary in terms of the extent of goal sharing, goal sharing becomes one of its measures. Even though the supply chain literature encourages goal sharing in a supply chain, the rational goal optimization paradigm suggests that organizations coordinate with others to maximize their own goal attainment (Hall and Foster, 1977; Heiner, 1983). It is therefore possible to observe different goal-sharing behaviours (Eisenhardt, 1989). Organizations may choose to maximize their own goals (being self-satisfying), maximize collective goals, or maximize others' goals.

Decision coordination behaviours may also vary in terms of the extent of risk sharing. Organizations may choose to take all or most of the risk, or avoid risk by 
Revised manuscript submitted to SCM:AIJ Special Issue on Decision Making and Analysis within Supply Chains dd. 2-March-2009

passing it to other organizations (being risk averse), or seek for an equal sharing of risk (Friedman and Savage, 1948; Arrow, 1951). Risk-sharing behaviour is an important measure because it may affect ordering and coordination behaviour. It is suggested that a risk-averse retailer will order less speculatively than a risk-loving retailer (Agrawal and Seshadri, 2000). Furthermore, a self-satisfying and riskavoiding decision-maker will be perceived as less collaborative and such a perception will lead to the failure of coordination effort.

\subsubsection{Ordering Behaviour}

Ordering behaviour in a supply chain context is reflected by the batch-size and frequency of customer orders. Typically in a push environment, orders are less frequent but larger in batch-size. In a pull environment, orders are more frequent but smaller in batch-size. Of course, some supply chain members may apply a combination of push and pull principles in their ordering routines. The most important measure for ordering behaviour for this study is the extent to which orders are being speculative (pushed) or pulled because they are very crucial in influencing flow behaviour (Lee et al., 1997).

In addition to the above mentioned ordering behaviours, a supply chain member may apply some inventory re-ordering policies which determine the batchsizes and frequencies of orders. For example, a continuous review re-ordering system may involve fixed-order-quantity policy, fixed-order-frequency policy or order-up-to policy. In some supply chains all members may strictly adhere to some of these reordering policies but some of them may switch from one policy to other policies occasionally. Some recent studies have demonstrated that different retailers may exhibit different ordering behaviours even though for the same products (e.g. Holmstrom, 1997 and Wong et al., 2005). 
Revised manuscript submitted to SCM:AIJ Special Issue on Decision Making and Analysis within Supply Chains dd. 2-March-2009

\subsubsection{Flow Behaviour}

Flow behaviour is simply the extent to which supply meets demand (Simatupang et al., 2002). Flow behaviour becomes undesirable when supply exceeds demand or demand exceeds supply. Undesirable flow behaviours were first demonstrated by Jay Forrester (1958). He showed that the mismatch of supply and demand can be amplified when demand information is amplified and delayed in industries. This phenomenon is called industrial dynamics (Forrester, 1958) or bullwhip effect (Lee et al., 1997). Typically bullwhip effect in industries consists of unpredictable waves of "supply exceeding demand" and "demand exceeding supply." When supply exceeds demand, there will be excessive inventory in the supply chain. When demand exceeds supply, the supply chain will suffer from excessive stock-out and lost sales.

\subsection{The theoretical framework of inter-organizational decision}

coordination

The above five theoretical constructs and their measures are considered the building blocks for the development of a theoretical framework of inter-organizational decision coordination. To develop the theoretical framework we adapted the theory of choice proposed by March and Olsen (1975) because it explicitly relates mental models to decision-making behaviour. The following four points explain how the five constructs are theoretically related to each other.

- Individuals' decision-making process can be affected by their cognitions, preferences and sense-making processes (construct: mental model). Plenty of decision-making literature has proven the roles of mental models in influencing decision-making processes (e.g. Kiesler and Sproull, 1982; Allison and Hayes, 1996; Kurtz and Snowden, 2003; Hopp, 2004). Organizational 
Revised manuscript submitted to SCM:AIJ Special Issue on Decision Making and Analysis within Supply Chains dd. 2-March-2009

mental models can usually be classified as either being analytic or generative (measures for mental model);

- Based on individuals' mental models and the interpretation of their business environment (in a supply chain context, we refer to the flow behaviour), decision-makers make decisions in certain manners (construct: decisionmaking behaviours). Decision-making behaviours can be observed based on problem causal attribution, goal-setting behaviours, and risk-taking attitudes (measures for decision-making behaviour);

- When the attainment of an organizational goal depends on the decisions of other supply chain members, they coordinate decisions with each other (construct: coordination behaviour). Since March and Olsen's (1975) theory is applicable to a single organization we extended their theory to the interorganizational setting. In an inter-organizational setting, the coordination of decisions may involve goal sharing and risk sharing among supply chain members (measures for coordination behaviour);

- As a result of decision coordination, supply chain members then respond by means of ordering decisions (construct: ordering behaviour) which usually aim at improving material flows (construct: flow behaviours). Some previous studies (e.g. Clark and Hammond, 1997) have established the linkage between ordering behaviour and flow behaviour.

$<<$ Please insert figure 2 around here $>>$

To illustrate the inter-relationships between the five constructs, figure 2 exemplifies how a supplier and a customer in a supply chain coordinate their ordering decisions. 
Revised manuscript submitted to SCM:AIJ Special Issue on Decision Making and Analysis within Supply Chains dd. 2-March-2009

In order to accommodate the possibility of a coordinated and an uncoordinated situation, two routes have been added into figure 2: route (1) refers to the situation when the supplier and customer decide not to coordinate decisions; route (2) refers to the situation when both parties decide to coordinate decisions. In both routes the decision-makers may need to anticipate the decision behaviour of the others or they may figure out the best approach to coordinate with the other parties to ensure that their goals are attained. Due to the asymmetric of mental models, information and goals, it is expected to find different supply chain members exhibiting different decision-making and coordination behaviours (Akkermans et al., 1999).

One of the potential contributions of the theoretical framework is that it allows us to examine and explain the relationships between mental models, decision-making behaviour, coordination behaviour, ordering behaviour and flow behaviour. By examining these relationships using the established measures it is possible to reveal conditions which lead to undesirable mental models, decision-making behaviour and coordination behaviour. Instead of relating poor flow behaviour to merely inappropriate ordering decisions (which is common for most literature), this framework dwells into its root causes and therefore potentially leads to enhanced insights and understanding of inter-organizational decision coordination.

\section{Research methodology}

Using the theoretical framework of inter-organizational decision coordination, we investigated how a supplier and its customers decided and coordinated their decisions to respond to their observed flow behaviours. Ideally researching such a phenomenon requires continuous monitoring of the flow behaviours, decision-making behaviours and coordination behaviours of all involved parties. Typical research methods such as survey, interview, and retrospective case study may not be suitable because no 
Revised manuscript submitted to SCM:AIJ Special Issue on Decision Making and Analysis within Supply Chains dd. 2-March-2009

respondent can be fully aware of the mental models and decision-making processes of other parties. Instead, this study needs longitudinal (real-time) multiple case studies (Yin, 1994) to allow researchers to observe and participate in the decision-making and coordination processes of all involved parties.

In this study, a longitudinal case study is conducted between a European toy supplier and three of its major retail customers in countries (see Table III). The toy supplier produced toy products from mostly its European factories. The three European retailers were asked to participate in the case study because they were willing to allow the researcher to participate in their decision-making processes. Since these three customers purchased the same toy products from the same supplier, their decisions would definitely influence one another. This complex inter-dependency between decisions of multiple parties in a supply chain is the exact phenomenon of our interest.

$<<$ Please insert Table III around here $>>$

Table III further explains the data collection protocol of the case studies. The researcher participated in the bi-monthly coordination meetings to observe decision coordination processes. To obtain an in-depth understanding of the mental model and decision-making behaviours with respect to a particular observed ordering and flow behaviour, follow-up interviews (guided by semi-structured questionnaires based on the theoretical framework) were then conducted with the involved parties. Furthermore, actual retailer demand data (order behaviours) of 20 products (which were discussed in the coordination meetings) are collected from the toy supplier's ERP system and retailers' EPOS data to triangulate with the observations made in the 
Revised manuscript submitted to SCM:AIJ Special Issue on Decision Making and Analysis within Supply Chains dd. 2-March-2009

coordination processes. Such multiple data sources allow for the triangulation of quantitative and qualitative data (Mentzer and Flint, 1997; Naslund, 2002; Mangan et al., 2004). With this research design, it was then possible to apply and test the theoretical framework of decision coordination (Argyris, 1979; McCutcheon and Meredith, 1993).

\section{Findings}

This section describes the findings of the individual cases of coordination between the toy supplier and three customers. It is then followed by a cross-case analysis and a discussion of the key findings.

\subsection{Coordination between the toy supplier and retailer $A$}

Retailer A was one of the biggest customers of the toy supplier. Retailer A was a toy specialist with approximately 180 stores in Nordic countries. The retailer purchased all the toy supplier's products (full assortment) all year round. The retailer re-ordered to fill their shelves "up to" the pre-determined inventory levels on a daily basis using an automatic replenishment system. The toy supplier was asked to replenish daily to the retailer's 180 stores. This is a typical just-in-time ordering behaviour (Wong et al., 2005).

$<<$ Please insert Table IV around here $>>$

Table IV summaries the decision coordination process between the toy supplier and retailer A. Frequent stock-out (flow behaviour) was the main trigger for decision coordination between the toy supplier and retailer A. Historically, order fill-rates had been low especially during the last two months of every year. Especially for the 20 
Revised manuscript submitted to SCM:AIJ Special Issue on Decision Making and Analysis within Supply Chains dd. 2-March-2009

products, stock-out at both the retailer's stores and supplier's distribution centre occurred even earlier than expected during the study. After experiencing stock-out again and again, the unsatisfied retailer $\mathrm{A}$ initiated decision coordination and pressured the top management of the toy supplier to solve the repeating stock-out (flow behaviour) problem.

Subsequently, the top management instructed their planners to improve the fill-rates. The planners initially attempted to make detailed investigation of the causes behind the stock-out (analytical mental model). However, they discovered that stockout for a product occurred from time to time without any consistent and logical reason. They could not conclude how the undesirable flow behaviour occurred. Then, they intuitively considered every product as having an equal chance of shortage (risktaking attitude); this means they switched their view on the cause and effect of the stock-out from a knowable to a complex situation (switched to intuitive reasoning).

Since the reasons of repetitive stock-out could not be well understood, the supplier considered the problem very difficult to solve and the effectiveness of any solution would be luck-dependent (decision-making behaviour). They also believed that the stock-out issue would be resolved if retailer A were to order earlier with larger batch-size (this means asking the retailer to order speculatively). This represents an external attribution of undesirable flow behaviour according to attribution theory. Finally, the planners chose to increase the re-order levels of the distribution centre for all products because they knew for sure this would reduce shortage (the use of simple but rather irrational rules). This decision actually increased the inventory risk faced by the supplier. However, the planners defended this decision by arguing that it was "rational" because it satisfied the top management's command to improve the fill-rates of the retailer A. They offered three explanations to this 
Revised manuscript submitted to SCM:AIJ Special Issue on Decision Making and Analysis within Supply Chains dd. 2-March-2009

decision: (1) avoid punishment by the top management; (2) avoid the risk of lost sales; (3) the top management could not possibly identify the reasons of overproduction.

Despite the stock-out problem, retailer A insisted on ordering in a just-in-time (pull) basis. Retailer A pushed the risk of inventory to the toy supplier by using its buying power. By pressuring the top management of the toy supplier the toy retailer managed to maximize its own goals. Finally, the deliberate increase in re-order levels successfully reduced stock-out of some products, but increased inventory levels of some products at the supplier's distribution centre. Eventually it was more or less a zero-sum game - retailer A gained benefit from the better fill rates but the toy retailer had to pay more for the higher inventory level.

\subsection{Coordination between the toy supplier and retailer $B$}

Retailer B was one of the biggest European customers for the toy supplier. The retailer had thousands of high-end department stores in Europe. Usually, the toy supplier was asked to deliver pallet-size shipments to the retailer's central warehouses on a monthly basis. The warehouses then replenished toy products to the stores. The retailer purchased all the supplier's products (full assortment) all year round. The retailer preferred to get discounts for placing large-quantity orders with long leadtimes, especially Christmas products.

$<<$ Please insert Table $\mathrm{V}$ around here $>>$

The coordination between the toy supplier and retailer B is summarized in Table V. Most coordination meetings were triggered by high level of year-end stock after the Christmas sales. Retailer B often discovered that more than $20 \%$ of the toys purchased 
Revised manuscript submitted to SCM:AIJ Special Issue on Decision Making and Analysis within Supply Chains dd. 2-March-2009

in the previous year were still left over in their central warehouses. Retailer B often pressured the toy supplier to take the excess inventory back or otherwise they would not authorize new orders. Due to these conflicting problems the toy supplier was not able to sell their new products as forecasted and subsequently ended up with high levels of inventory. There had been, previously, several attempts to investigate the cause and effect of this flow behaviour but all of them failed due to the high level of complexity, according to the supply chain planners.

Every year there was a coordination process to decide the orders for the coming Christmas season. Since all the 20 selected products were new, both parties intuitively estimated the Christmas demands (intuitive mental model). Retailer B promised to provide demand forecasts but committed no responsibility to the forecasts (being risk avoidance). Since there was no formal and detail analysis their mental models are considered as being generative reasoning. They did not apply an analytic approach because their past experience and knowledge told them that there would be a high level of year-end stock, no matter what they decided. They both attributed the causes of flow behaviours as being luck dependent and market dependent (external attribution).

Later, the toy supplier decided to provide discounts so that retailer B would place early and large orders for the Christmas period. The retailer received largequantity deliveries before Christmas without expecting replenishment. Both parties believed early-order discounts guarantee availability and sales. Unlike retailer A, Retailer B believed that the best way to deal with the Christmas-related products was to secure inventory and discount and then use the discount whenever sales were not performing as expected. Thus, the coordination of decisions involved mainly agreements of the ordering quantities and discounts. This sense-making trait is similar 
Revised manuscript submitted to SCM:AIJ Special Issue on Decision Making and Analysis within Supply Chains dd. 2-March-2009

to the act-sense-respond (for a chaotic situation) even though in reality there is a chance to apply probe-sense-respond (in a complex situation).

In this case, both parties actually tried to maximize their own goals and avoid risk (decision-making behaviour). The toy supplier intended to achieve high revenues sooner and passed the risk of inventory to retailer B while retailer B wanted to secure bigger discounts and the availability of products. Retailer B recognized the inventory risk they needed to face but they knew they had the bargaining power to get the supplier to compensate the year-end stock, if it happened. Thus, both parties agreed to place orders three to five months prior to the Christmas season. They were both supremely optimistic on the effectiveness of early-order (speculating) behaviour.

Even with the early-orders, the supplier delayed some deliveries. Among the 20 products, only five of them were sold as forecast, five of them were under-forecast, while ten of them were forecast too high. Both parties actually anticipated similar situations, but they just did not know beforehand which products would be over or under-forecast. Again, there was an overall high level of year-end stock, which was as bad as previous years. Overall, this coordination process showed that both parties were applying the same mental model (being intuitive) and decisions over and over again every year. Decisions made were deliberately guided by the simple rule i.e. early-order discounts guarantee sales and availability. This belief was further strengthened by some of the observations that early-order discounts could occasionally lead to better sales and availability (for some products, shortage happened to retailer A but not retailer B). No-one managed to demonstrate an alternative ordering behaviour which could be more effective. This uncoordinated supply chain was simply governed by the pervasive mental models of both parties. 
Revised manuscript submitted to SCM:AIJ Special Issue on Decision Making and Analysis within Supply Chains dd. 2-March-2009

\subsection{Coordination between the toy supplier and retailer C}

Retailer C was one of the largest European customers for the toy supplier. Retailer C enjoyed high market shares in the European countries. Their stores were usually located at the high streets. Before initiating the coordination, the supplier was asked to deliver toys to the retailer's central warehouse as well as to the stores directly with varying batch-sizes and lead-times. Occasionally some large orders could be placed at the last minute. With this ordering behaviour, there were a few orders with large batch-sizes and long lead-times, and a few replenishment orders with smaller batchsizes and shorter lead-times. However, this unpredictable ordering behaviour was usually not well coordinated, resulting in high levels of obsolete inventory and stockout.

$<<$ Please insert Table VI around here $>>$

The coordination process between the toy supplier and retailer $\mathrm{C}$ is summarized in Table VI. The toy supplier initiated the coordination process with retailer $\mathrm{C}$ when they needed decisions for the orders for the Christmas season. First, both parties studied carefully their past experiences on Christmas sales and formulated forecast models of the expected sales for the Christmas campaign. Even though all the 20 selected products were new, both parties estimated the Christmas demands based on historical demands of similar products. They were being analytical and they both promised to be jointly responsible for the forecasts.

The decision-makers from both parties considered the flow behaviour as having a mix of knowable and complex cause and effect. Thus, they allocated discounts (smaller than those for retailer B) for all the 20 selected products, and 
Revised manuscript submitted to SCM:AIJ Special Issue on Decision Making and Analysis within Supply Chains dd. 2-March-2009

retailer C decided to place early-orders at the "safe" quantities. These "safe quantities" were the lowest expected sales quantities for the Christmas season. The choice of such safe quantities implies that they were neither supremely optimistic nor supremely pessimistic (decision-making behaviour). For each product they allocated discounts and contingency production plans to be executed when necessary. These allocated discounts and production plans could be transferred to other products if they were not needed later. This is similar to a sense-analyze-respond strategy.

In this case, both parties tried to internally attribute the flow problems to their own practices and decisions. They tried to share goals and risks. To achieve their joint strategy, they had to continuously share demand and supply information and they frequently engaged in coordination processes, especially when they observed undesirable flow behaviours. As expected, among the 20 products, only seven of them followed the forecasts; five of them were under-forecast; while the remaining was over-forecast. Since they had already some contingency plans, they managed to increase production for those under-forecast products and reduced production for those over-forecast products. To reduce stock-out, toys were delivered directly to the stores when necessary. Furthermore, additional discounts were allocated to reduce inventory levels, and losses due to additional discounts were shared among the two parties. Eventually both parties realized lower inventory levels and stock-out compared with the previous years.

\subsection{Cross-case analysis}

Comparing the data from the three cases, we found some interesting patterns of interorganizational coordination behaviour. Firstly, in all three cases, mental models and decision-making behaviours of the involved parties collectively affected their coordination and ordering behaviours and subsequently influenced flow behaviours. 
Revised manuscript submitted to SCM:AIJ Special Issue on Decision Making and Analysis within Supply Chains dd. 2-March-2009

Secondly, as illustrated in figure 3, different combinations of mental models and decision-making behaviours led to different flow behaviours. For the cases of coordination between the toy supplier and retailer A and B, the combination of the use of intuitive reasoning (mental model), external attribution (decision-making behaviour), risk avoidance and maximizing own or other's goals (coordination behaviour) eventually led to inappropriate ordering behaviours and poor flow behaviours. However, the combination of analytical reasoning (mental model), internal attribution (decision-making behaviour) and collective goal maximization (decision-coordination behaviour) was found to contribute to the improvement of flow behaviour.

$<<$ Please insert Figure 3 around here $>>$

Thirdly, the observed patterns of inter-organizational coordination behaviours from the three cases improve the explanations of poor flow behaviour rather than simply referring to either the lack of decision-making (cognitive) capability, coordination, or collaborative relationship (e.g. Akkermans et al., 1999; Simatupang et al., 2002; Knoppen and Christiaanse, 2007). The explanations we discovered from the case analyses are more actionable. Most managers are already aware of the need for decision coordination and collaboration but what they need to understand is the conditions which lead to the use of (un)desirable mental models and decision behaviours. The following three paragraphs provide such novel explanations for each case of coordination between the toy supplier and the three retailers (figure 3).

When the toy supplier coordinated decisions with retailer $\mathrm{B}$, both parties believed that the cause and effect leading to poor flow behaviour could not be 
Revised manuscript submitted to SCM:AIJ Special Issue on Decision Making and Analysis within Supply Chains dd. 2-March-2009

understood and therefore it was not possible to improve flow behaviour. With the belief of the absence of cognitive capability in understanding flow behaviour, decision-makers from both parties attempted to attribute the flow problems externally and avoided taking the risk of their decisions. According to the theory of complex adaptive system (CSA), decision-makers in a complex environment (most supply networks) will tend to follow simple decision rules (Pathak et al., 2007). They are then caught in a reinforcing loop of a vicious cycle (Akkermans et al., 1999) because decision-makers often end up choosing predictable and simple rules in their decisionmaking process after repetitively facing uncertain conditions (Heiner, 1983). The lesson learnt from this case is that supply chain managers need to be aware of the fact that such simple decision rules become harmful especially when they are guided by an undesirable mental model (in this case the belief of inadequate cognitive capability) and the tendency to attribute the problem externally.

The coordination with retailer A shows that even though there was a belief that the cause and effect of flow behaviour could be explained, the toy supplier and retailer A did not finally manage to choose a more effective ordering behaviour. The coordination between the toy supplier and retailer A was somewhat similar to the above situation except that there was an attempt to investigate (being analytical) the cause and effect of poor flow behaviour. Such an attempt could have successfully led to better coordination; however, the working environment provided by the top management had indeed caused the planners to give up the rational mental model. Since the top management put more emphasis on the improvement of fill rates for retailer A rather than the overall flow behaviour, the planners ended up attributing the poor flow problem externally and chose to maximize the goals of retailer A. In this case, the top management of the toy supplier, though having good intention, did not 
Revised manuscript submitted to SCM:AIJ Special Issue on Decision Making and Analysis within Supply Chains dd. 2-March-2009

realise that their behaviours had led to a negative influence on the mental models and decision-making behaviours of the planners. This explanation adds insights to Akkermans et al.'s (1999) explanation of the lack of top management awareness by highlighting that top management behaviours can lead to undesirable decision-making and coordination behaviours.

Unlike the above two cases, the coordination process between the supplier and retailer $\mathrm{C}$ was successful in improving the flow behaviour for the both parties. In this case both parties applied analytical reasoning because they believed that the cause and effect of the flow behaviour was knowable. Another crucial condition which contributed to the successful coordination and maximization collective goals was that both parties did not attribute the flow problem externally but put effort into working together to optimize the overall flow behaviour. Without these conditions it was impossible for both parties to share risk together and apply the sense-analyze-respond approach to improve the flow behaviour. Under all the above conditions, the toy supplier and retailer $\mathrm{C}$ managed to develop a re-ordering system which allowed them to place a combination of large and small batch-size orders by frequently observing actual consumer demand.

\section{Discussion and implications}

The three cases reveal the complexity in coordinating ordering decisions in a toy supply network as a result of the differences in mental models, decision-making behaviours and coordination behaviours. If this study were carried out by collecting data about flow behaviours and ordering behaviours without examining the roles of mental model then it would at best refer to "inappropriate ordering behaviour" as the reason for observed poor flow behaviours. There would be no novel finding. Instead, based on the theoretical framework of this article, this study reveals five key findings 
Revised manuscript submitted to SCM:AIJ Special Issue on Decision Making and Analysis within Supply Chains dd. 2-March-2009

regarding the decision logics and crucial factors which could influence decisionmaking behaviours and coordination behaviours in an interorganizational setting.

The first key finding is the fact that even observing the same flow behaviour of the same product, different parties responded with different decision-making behaviours, coordination behaviours and ordering behaviours. From the case study one of the reasons for such a different response is the fact that different parties have different mental models and different objectives (Day and Lord, 1992). Furthermore, in the coordination with retailer $\mathrm{A}$ and $\mathrm{B}$, decision-makers were simply confused about the choice of their objectives (March and Olsen, 1975) and made decisions based on bias judgment (Mintzberg et al., 1998) or intuition (Senge, 1990). Such a situation emerged when the mental models of the toy supplier and the retailers considered the cause and effect of flow behaviour as being too complex to understand instead of being knowable (Kurtz and Snowden, 2003). When cause and effect is perceived as being too complex, decision-makers tend to apply simple rules guided by their own judgment and such decision-making behaviour is often biased. The implication of this finding, to supply chain managers, is that there is a need to communicate with their customers and suppliers to clarify their mental models about the cause and effect of flow behaviour.

The second finding helps to further explain the first finding. In order to ensure that a decision-maker is able to respond with the right ordering behaviour to the observed flow behaviour, this study reveals that there is a need to ensure the coexistence of several conditions - analytic reasoning (mental model), internal attribution and risk neutral (decision-making behaviours), goal and risk-sharing (coordination behaviours). Any departure from these conditions is likely to result in undesirable ordering behaviour. More importantly, top managers need to be aware 
Revised manuscript submitted to SCM:AIJ Special Issue on Decision Making and Analysis within Supply Chains dd. 2-March-2009

that even though they intend to improve flow behaviours in their supply network some of their behaviour can will actually alter the above conditions and therefore influence the decision-making and coordination processes. For example, the emphasis to improve fill rates for retailer A led to confusion, judgment bias and the choice of intuitive reasoning, external attribution, risk-avoidance and self-satisfying goal setting (Mintzberg et al., 1998; Sadler-Smith, 2004). Also, in both coordination efforts with retailer $\mathrm{A}$ and $\mathrm{B}$, the choices of maximizing their own and other goals were partly promoted by the use of external attribution (attribute flow problems to luck, task difficulty and other parties) and the existence of such a decision-making behaviour is usually due to weaknesses of the reward system and goal-setting culture (Weiner, 1972; Kelly, 1973; Simatupang et al., 2002). In this study, decision-makers chose to attribute externally because they were either afraid of punishment or realizing that it was impossible to relate the consequences of their decisions in such a complex supply network. Instead of attributing problems externally, this study informs us that it is more effective to attribute problems internally. Managers should build a decision (attribute) process that first examines own mental models and assumptions instead of merely blaming the other external (environmental) factors. Furthermore, managers need to discover the mental models of each decision-maker especially when decisions are made under uncertainty (Baird, 1989).

The third finding focuses on the use of intuitive reasoning. People often rely on intuitions when the environment becomes complex or chaotic. Even though all managers prefer intuitive reasoning (Senge, 1990; Mintzberg and Westly; 2001), this study reveals that it is not always beneficial to be intuitive. The coordination with retailer $\mathrm{B}$ demonstrated to us that a perceived complex environment was not as complex as it seemed - it was actually analyzable. If managers do not confront the 
Revised manuscript submitted to SCM:AIJ Special Issue on Decision Making and Analysis within Supply Chains dd. 2-March-2009

preference of using intuitive reasoning in their organizations, people will continue doing what they usually do and telling each other "this is just the way we usually do things here" and end up with ineffective learning (Senge, 1990). Another problem is that people often refer to uncertainty to justify the use of intuitive reasoning but as uncertainty increases decision rules will tend to become more restrictive in eliminating particular actions or response patterns to potential information (Heiner, 1983). Thus, under high uncertainty decision rules applied by supply chain members become more predictable but the decisions may be self-satisfying (not sharing goal) in nature.

The fourth finding is the fact that individuals have limited rationality and evaluative capabilities (Simon, 1978) but they always believe that they have complete rationality. Even if the decisions people made were considered to be rational they might lead to the maximization of own goals but not collective goals. This study further reveals how the rationality of decision-making in an organization could be impaired by various decision behaviours in the supply chain. In this case, the planners of the toy supplier actually made decisions based on the information provided by all account managers and customers' purchase orders. However, different account managers had independently made deals with their customers in separate coordination meetings. The collective ordering behaviours of the three retailers were never coordinated with the planners who needed to plan for the same products for all these three customers. This situation further impaired the decision rationality of the planners. This practice led to irrational decisions and as a whole the supply chain could not achieve rational adaptation and learning (Knoppen and Christiaanse, 2007). Managers need to understand that one of the better criteria for a good decision is actually the extent to which the decision takes into account the 
Revised manuscript submitted to SCM:AIJ Special Issue on Decision Making and Analysis within Supply Chains dd. 2-March-2009

related decision and coordination behaviours (goals, goal-sharing and risk-sharing attitudes) of other supply chain members (Thomas and Griffin, 1996). An even more critical decision criterion is the sharing of mental models amongst decision-makers from different supply chain members despite the fact that they all observe the same flow behaviour.

Finally, managers need to understand how trusts in a supply network can be affected by decision and coordination behaviours. Trust is an essential enabler for inter-organizational adaptation (Knoppen and Christiaanse, 2007). In this study retailer B actually revealed that they would not trust any new initiatives brought forward by the toy supplier because the supplier had in the past pushed risk to the retailer despite making many sweet promises. Risk avoidance behaviour of one party usually promotes risk avoidance of the other parties and eventually leads to low trust between supply chain members (Agrawal and Seshadri, 2000). Keeping fairness in business relationships will usually promotes trust and lead to willingness to share goals. Considering the above findings, managers need to apply this new way of thinking about their decision-making and coordination behaviours.

\section{Conclusion}

This article develops a framework which allows us to investigate the interaction and coordination of decision-making processes in a supply chain with multiple and interdependent suppliers and customers. The framework is applied to study the coordination of decisions between a toy supplier and three retailers. The main contribution of this study is the use of an alternative research approach to understand the coordination of decisions in a multi-echelon supply chain by incorporating decision-making theory into logistics and supply chain literature. Its key findings add new knowledge about the impacts of different mental models and decision-making 
Revised manuscript submitted to SCM:AIJ Special Issue on Decision Making and Analysis within Supply Chains dd. 2-March-2009

behaviours on inter-organizational decision coordination. They provide actionable explanations to poor flow behaviour by revealing the undesirable conditions and mental models which lead to poor coordination behaviours and ordering behaviours.

Every piece of research has its limitations. Even though it was well guided by the proposed framework, we realized that it was not always possible to directly observe the mental models of every supply member. In some cases, an inferential interpretation was made. Skinner (1987) criticized this approach by saying "we cannot directly observe mental phenomena." However, this study has enhanced our understanding of the roles of mental models in the decision and coordination behaviours in a supply chain. Another problem is that the study did not consider the interactions of decision coordination between the three retailers and other toy suppliers, which could influence the decisions of the three retailers. It would be ideal if we were able to involve many retailers and many suppliers. However this seems to be too difficult to achieve because it requires significant management and researcher time and it may be impossible to find companies (competitors) to get involved in such a study together.

\section{References}

Agrawal, V. and Seshadri, S., (2000), "Risk intermediation in supply chains", IIE Transactions, Vol. 32 No. 9, pp. 819-831.

Akkermans, H., Bogerd, P. and Vos, B. (1999), "Virtuous and vicious cycles on the road towards international supply chain management", International Journal of Operations \& Production Management, Vol. 19 No. 5/6, pp. 565-581.

Allison, C.W. and Hayes, J. (1996), "The cognitive style index: a measure of intuition-analysis for organizational research”, Journal of Management Studies, Vol. 33, pp. 119-135. 
Revised manuscript submitted to SCM:AIJ Special Issue on Decision Making and Analysis within Supply Chains dd. 2-March-2009

Argyris, C. (1979), "Using qualitative data to test theories", Administrative Science Quarterly, Vol. 24 No. 4, pp. 672-679.

Arrow, K.J. (1951), “Alternative approaches to the theory of choice in risk-taking situations", Econometrica: Journal of the Econometric Society, Vol. 19 No. 4, pp. 404-437.

Baird, B.V.F. (1989), Managerial decisions under uncertainty: An introduction to the analysis of decision making, John Wiley \& Son, Inc., New York.

Barr, P.S., Stimpert, J.L. and Huff A.S. (1992), “Cognitive change, strategic action, and organizational renewal", Strategic Management Journal, Vol. 13, pp.15-36.

Boddy, D., MacBeth, D. and Wagner, B. (2000), "Implementing collaboration between organizations: an empirical study of supply chain partnering”, Journal of Management Studies, Vol. 37 No. 7, pp. 1003-1017.

Bogner, W.C. and Barr, P.S. (2000), "Making sense in hypercompetitive environments: a cognitive explanation for the persistence of high velocity competition”, Organization Science, Vol. 11 No. 2, pp. 212-226.

Clark, A.J. and Scarf, H. (1960), “Optimal policies for a multi-echelon inventory problem”, Management Science, Vol. 6 No. 4, pp. 475-490.

Clark, T.H. and Hammond, J.H. (1997), "Reengineering channel reorder process to improve total supply-chain performance", Production and Operations Management, Vol. 6 No. 3, pp. 248-265.

Day, D.V. and Lord R.G. (1992), "Expertise and problem categorization: The role of expert processing in organizational sense-making", Journal of Management Studies, Vol. 29, pp. 35-47.

De Wit, B. and Meyer, R. (2004), Strategy: Process, content and context ( $3^{\text {rd }}$ Ed.), Thompson Learning, London. 
Revised manuscript submitted to SCM:AIJ Special Issue on Decision Making and Analysis within Supply Chains dd. 2-March-2009

Dyer, J.H. and Singh, H. (1998), "The relational view: cooperative strategy and sources of interorganizational competitive advantage", Academy of Management Review, Vol. 23 No. 4, pp. 660-679.

Eisenhardt, K.M. (1989), “Agency theory: An assessment and review”, The Academy of Management Review, Vol. 14 No. 1, pp. 57-74.

Forrester, J. (1958), "Industrial dynamic, a major breakthrough for decision makers", Harvard Business Review, Vol. 36 No. 4, pp. 37-66.

Friedman, M. and Savage, L.P. (1948), "The utility analysis of choices involving risk”, Journal of Political Economy, Vol. 56, pp. 279-304.

Hall, D.T. and Foster, L.W. (1997), “A psychological success cycle and goal setting: goals, performance, and attitudes”, Academy of Management Journal, Vol. 20, pp. 282-290.

Heiner, R.A. (1983), “The origin of predictable behavior”, The American Economic Review, Vol. 73 No 4, pp. 560-595.

Hill R.C. and Levenhagen, M. (1995), “Metaphors and Mental Models: Sense-making and Sense-giving in Innovative and Entrepreneurial Activities", Journal of Management, Vol. 21 No. 6, pp. 1057-1074.

Hodgkinson, G.P., Bown, N.J., Maule, A.J., Glaister, K.W. and Pearman, A.D. (1999), "Breaking the frame: an analysis of strategic cognition and decision making under uncertainty", Strategic Management Journal, Vol. 30, pp. 977-985.

Holmstrom, J. (1997), "Product range management: a case study of the supply chain operations in the European grocery industry", Supply Chain Management, Vol. 2 No. 3, pp. 107-115.

Hopp, W.J. (2004), “Fifth years of management science”, Management Science, Vol. 50 No. 1, pp. 1-7. 
Revised manuscript submitted to SCM:AIJ Special Issue on Decision Making and Analysis within Supply Chains dd. 2-March-2009

Kelly, H.H. (1973), “The process of casual attribution”, American Psychologist, Vol. 28, pp. 107-128.

Kiesler, S. and Sproull, L. (1982), "Managerial response to changing environment: perspectives on problem sensing from social cognition", Administrative Science Quarterly, Vol. 27, pp. 548-570.

Knight, D, Pearce, C.L., Smith, K.G., Olian, J.D., Sims, H.P., Smith, K.A. and Flood, P. (1999), "Top management team diversity, group process, and strategy consensus", Strategic Management Journal, Vol. 20 No.5, pp. 445-465.

Knoppen, D. and Christiaanse, E. (2007), “Interorganizational adaptation in supply chains: a behavioral perspective", The International Journal of Logistics Management, Vol. 18 No. 2, pp. 217-237.

Kurtz, C.F. and Snowden, D.J. (2003), “The new dynamics of strategy: Sense-making in a complex and complicated world”, IBM Systems Journal, Vol. 42 No. 3, pp. $462-483$.

Lane, P.J. and Lubatkin, M. (19998), "Relative absorption capacity and interorganizational learning”, Strategic Management Journal, Vol. 19, pp. 461477.

Lee, H.L., Padmanabhan, V. and Whang, S. (1997), “The Bullwhip effects in supply chains", Sloan Management Review, Vol. 38 No. 3, pp. 93-102.

Lewis I. and Talalayevsky A. (1997), "Logistics and information technology: A coordination perspective", Journal of Business Logistics, Vol. 18 No. 1, pp. 141157.

Malone, T.W. and Crowston, K. (1994), "The interdisciplinary study of coordination", ACM Computing Science, Vol. 26 No 1, pp. 87-119. 
Revised manuscript submitted to SCM:AIJ Special Issue on Decision Making and Analysis within Supply Chains dd. 2-March-2009

Mangan, J., Chandra, L. and Gardner, B. (2004), "Combining quantitative and qualitative methodologies in logistics research", International Journal of Physical Distribution and Logistics Management, Vol. 34 No. 7/8, pp. 565-578.

March, J.G. and Olsen, J.P. (1979), Ambiguity and Choice in Organizations, Universitetsforlaget.

McCutcheon, D.M. and Meredith, J.R. (1993), "Conducting case study research in operations management", Journal of Operations Management, Vol. 11 No. 3, pp. 239-256.

Metzger, J.T. and Flint, D.J. (1997), "Validity in logistics research", Journal of Business Logistics, Vol. 18 No. 1, pp. 199-216.

Mintzberg, H. and Westly F. (2001), "Decision-making: it is not what you think", MIT Sloan Management Review, Vol. 42 No. 3, pp. 89-93.

Mintzberg, H., Ahlstrand, B. and Lampel, J. (1998), Strategy safari: A guide tour through the wilds of strategic management, Prentice- Hall, Hemel Hempstead.

Metters, R. (1997), "Quantifying the bullwhip effect in supply chains”, Journal of Operations Management, Vol. 15 No. 2, pp. 89-100.

Naslund, D. (2002), “Logistics needs qualitative research - especially action research", International Journal of Physical Distribution and Logistics Management, Vol. 32 No. 5, pp. 321-338.

Pathak, S.D., Day, J.M., Nair, A., Sawaya, W. and Kristal, M.M. (2007), “Complexity and adaptivity in supply networks: building supply network theory using a complex adaptive systems perspective, Decision Sciences, Vol. 38 No. 4, pp. 547580.

Raiffa, H. (1968), Decision Analysis: Introductory lectures on choices under uncertainty, Mass: Addison-Wesley, Reading. 
Revised manuscript submitted to SCM:AIJ Special Issue on Decision Making and Analysis within Supply Chains dd. 2-March-2009

Sadler-Smith, E. (2004), "Cognitive style and the management of small and mediumsized enterprises”, Organization Studies, Vol. 25 No. 2, pp. 155-181.

Sahin, F. and Robinson, E. P. (2002), "Flow coordination and information sharing in supply chains: review, implications, and directions for future research", Decision Sciences, Vol. 33 No. 4, pp. 505-536.

Scott, W.G. (1961), “Organization theory: An overview and appraisal”, Journal of the Academy of Management, Vol. 4 No. 1, pp. 7-26.

Senge, P.M. (1990), The fifth discipline: The art \& practice of the learning organization, Random House, London.

Simatupang, T.M., Wright, A.C. and Sridharan, R. (2002), "The knowledge of coordination for supply chain integration", Business Process Management Journal, Vol. 8 No. 3, pp. 289-308.

Silver, E.A. (1981), “Operations research in inventory management: a review and critique", Operations Research, Vol. 29 No. 4, pp. 628-645.

Skinner, B.F. (1987), Upon further reflection, Englewood Cliffs, N.J.

Simon, H.A. (1978), "Rational decision making in business organizations", The American Economic Review, Vol. 69 No. 4, p. 493-513.

Surana, A., Kumara, S., Greaves, M., Raghavan, U.N., (2005), "Supply chain network: a complex adaptive systems perspective", International Journal of Production Research, Vol. 43, pp. 4235-4265.

Thomas, D.J. and Griffin, P.M. (1996), “Coordinated Supply Chain Management”, European Journal of Operational Research, Vol. 94, pp. 1-15.

Weiner, B. (1972), Theories of motivation: From mechanism to cognition, Markham, Chicago. 
Revised manuscript submitted to SCM:AIJ Special Issue on Decision Making and Analysis within Supply Chains dd. 2-March-2009

Wong, C.Y., Arlbjørn, J.S. and Johansen, J. (2005), "Supply chain management practices in toy supply chains", Supply Chain Management: An International Journal, Vol. 10 No. 5, pp. 367-378.

Yin, R.K. (1994), Case study research: Design and methods, Sage Publications, Beverly Hills, CA. 
Revised manuscript submitted to SCM:AIJ Special Issue on Decision Making and Analysis within Supply Chains dd. 2-March-2009

Figure 1 Theoretical constructs and measures

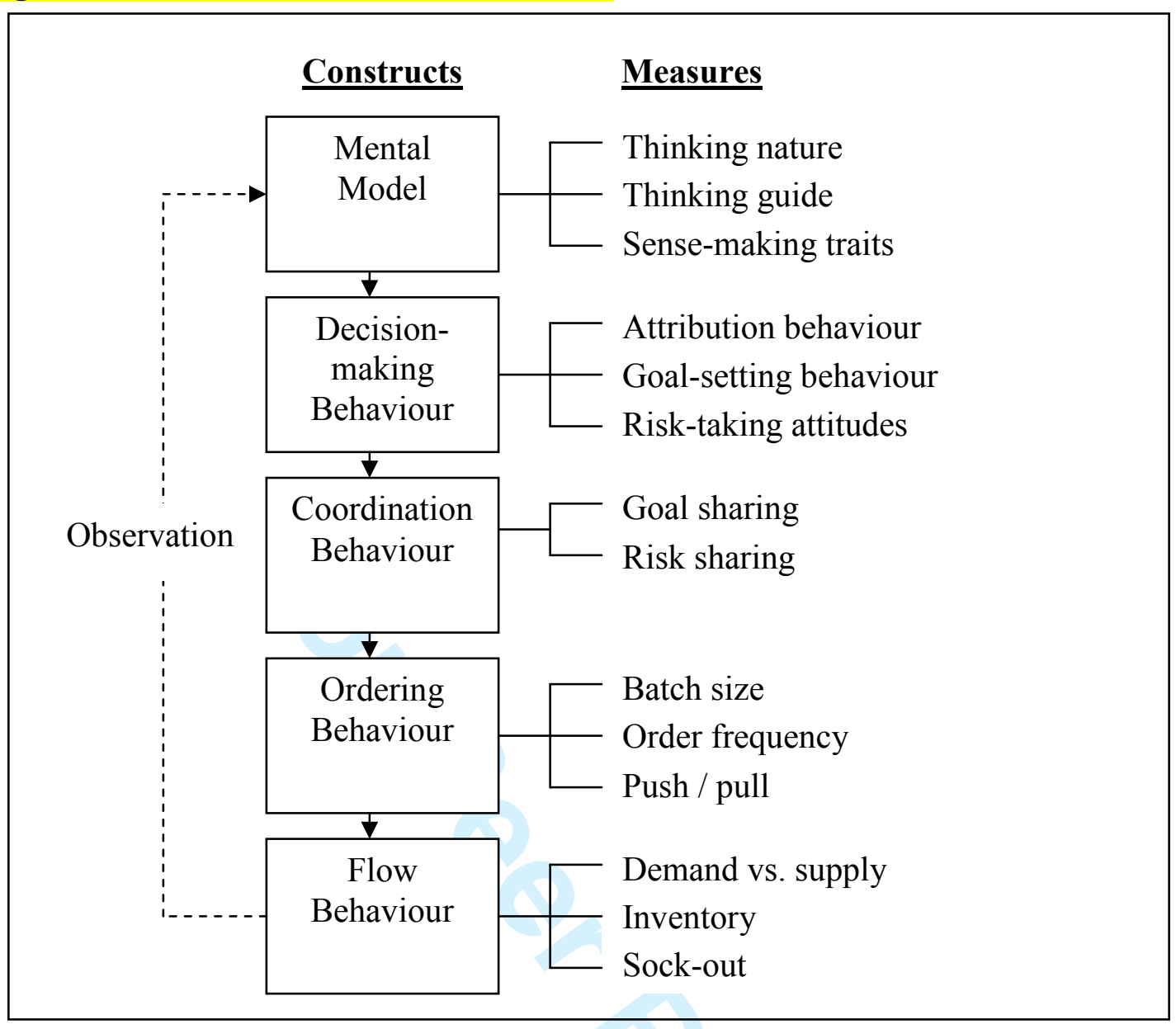

Figure 2 Theoretical framework of inter-organizational decision coordination

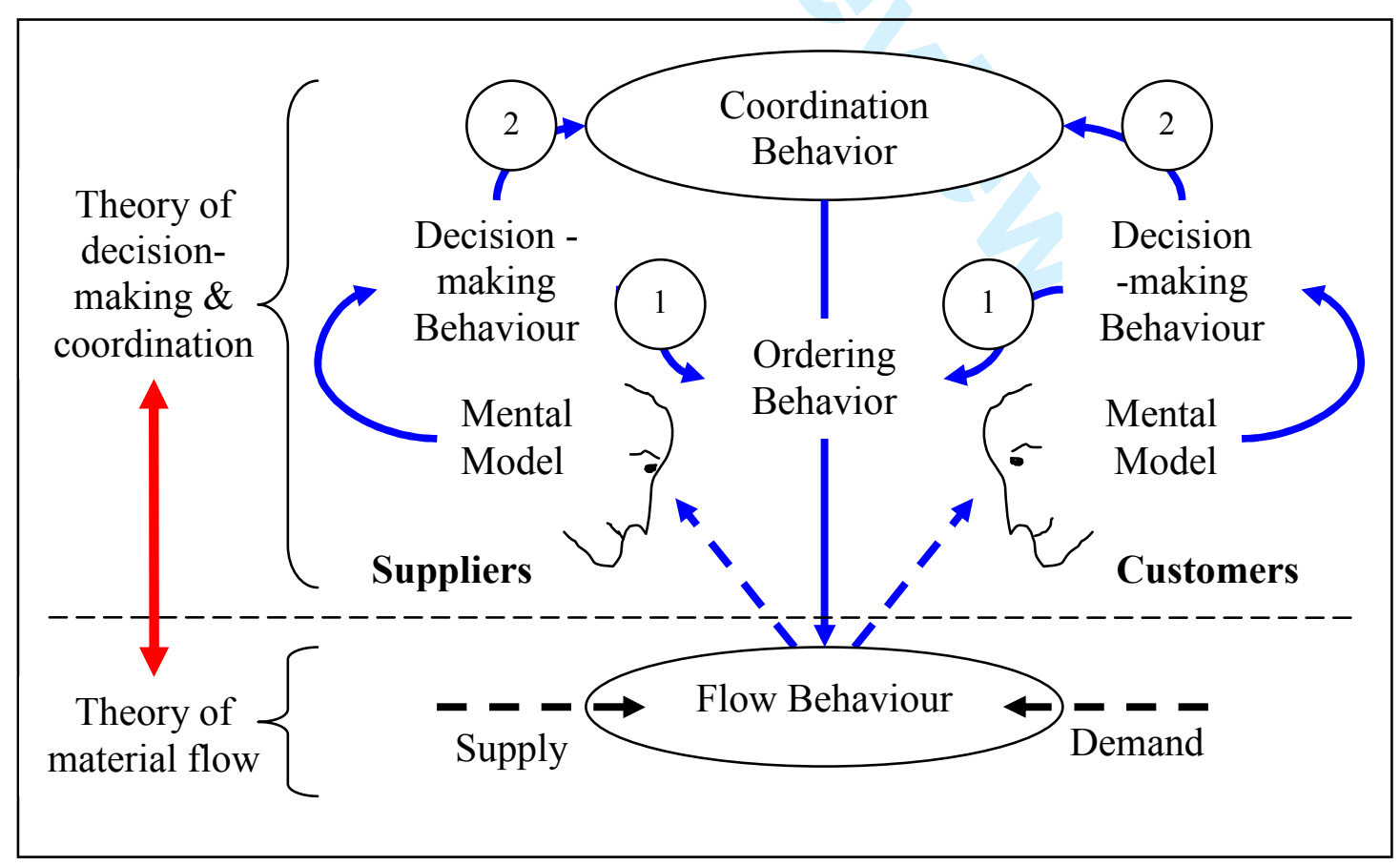


Revised manuscript submitted to SCM:AIJ Special Issue on Decision Making and Analysis within Supply Chains dd. 2-March-2009

Figure 3 Patterns of inter-organizational decision coordination

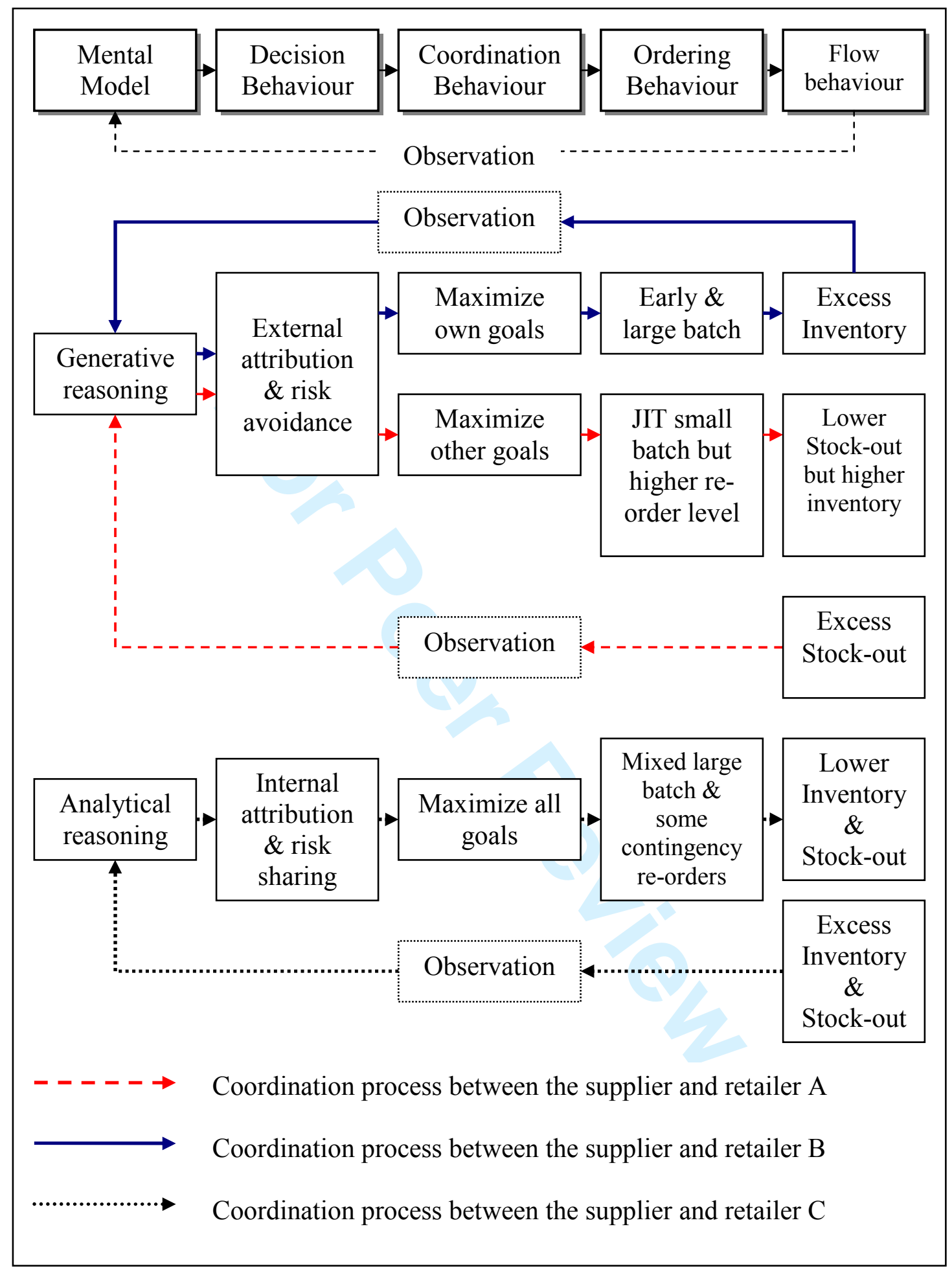


Revised manuscript submitted to SCM:AIJ Special Issue on Decision Making and Analysis within Supply Chains dd. 2-March-2009

Table I The two mental models (Adopted from De Wit and Meyer, 2005)

\begin{tabular}{lll}
\hline Characteristics & Rational (Analytic) & Generative (Intuitive) \\
\hline Thinking nature & Deductive and computational & Inductive and imaginative \\
\hline Thinking guides & Formal, fixed rules & Informal, variable rules \\
\hline Sense-making & Sense-categorize-respond (if & Probe-sense-respond (if \\
traits (cause and & known); & complex); \\
effect) & Sense-analyze-respond (if & Act-sense-respond (if chaotic) \\
& knowable) & \\
\hline Learning source & Confirm cause and effect & Judge cause and effect \\
\hline
\end{tabular}

Table II Three types of ordering behaviour (Adopted from Wong et al., 2005)

\begin{tabular}{llll}
\hline $\begin{array}{l}\text { Ordering } \\
\text { behaviour }\end{array}$ & Just-in-time (JIT) & $\begin{array}{l}\text { Mixed of JIT and } \\
\text { large-batches }\end{array}$ & $\begin{array}{l}\text { One-off large } \\
\text { batches }\end{array}$ \\
\hline Order size & - Pieces & - Boxes & - Pallets/containers \\
\hline Order frequency & - Daily & - Weekly or & - Monthly or \\
& & monthly & quarterly \\
\hline $\begin{array}{l}\text { Push / Pull in } \\
\text { ordering }\end{array}$ & - Pull & - Mixed push \& pull & - Push \\
\hline
\end{tabular}


Revised manuscript submitted to SCM:AIJ Special Issue on Decision Making and Analysis within Supply Chains dd. 2-March-2009

Table III Research design for three case studies

\begin{tabular}{llll}
\hline Background & Retailer A & Retailer B & Retailer C \\
\hline Retail type & - Toy specialist & - Department store & - Toy specialist \\
Countries & - Nordics & - Central Europe & - Central Europe \\
No. of stores & - 180 & - 80 & - 26 \\
\hline Usual flow & - Excessive stock- & - Excessive & - Mixed of \\
behaviour & out during & inventory after & excessive stock- \\
& Christmas season & Christmas season & out and excessive \\
& & & inventory \\
\hline Research design/ & - Data about decision-making behaviour and coordination \\
Data collection & behaviour are collected from the minutes of bi-monthly or \\
(guided by the & monthly coordination meetings & \\
constructs and & - Data about flow behaviour and ordering behaviour are based \\
measures in & on actual retailer demand and supply data of the 20 selected \\
Figure 1, which & products \\
are defined in & - Follow-up interviews with the buyers from the 3 toy retailers \\
Chapter 2) & and managers from the toy supplier to validate mental models \\
\hline & and the above data & \\
\hline
\end{tabular}


Revised manuscript submitted to SCM:AIJ Special Issue on Decision Making and Analysis within Supply Chains dd. 2-March-2009

Table IV Decision coordination between toy supplier and retailer A

\begin{tabular}{|c|c|}
\hline $\begin{array}{l}\text { Decision \& } \\
\text { coordination }\end{array}$ & $\begin{array}{l}\text { Interpretation and Data (based on interview, supply and } \\
\text { demand data, and meeting minutes) }\end{array}$ \\
\hline $\begin{array}{l}\text { 1. Observed flow } \\
\text { behaviour }\end{array}$ & $\begin{array}{l}\text { - Frequent stock-out (supply }<\text { demand) at the distribution } \\
\text { centre and toy stores; } \\
\text { - Order full rates of the } 20 \text { products as low as } 50 \% \text {; }\end{array}$ \\
\hline 2. Mental model & $\begin{array}{l}\text { - Analytic reasoning - toy supplier initiated detail investigations } \\
\text { of production \& inventory policies (fixed rules) and hoped to } \\
\text { sense-categorise-respond but failed to explain stock-out; } \\
\text { - Intuitive reasoning - finally concluded "it involves a complex } \\
\text { cause and effect" and switched to act-sense-respond; }\end{array}$ \\
\hline $\begin{array}{l}\text { 3. Decision- } \\
\text { making } \\
\text { behaviour }\end{array}$ & $\begin{array}{l}\text { - External attribution of root cause - toy supplier concluded that } \\
\text { "sometime we are lucky but often we are not" and toy retailer } \\
\text { blamed short supply for causing the stock-out; } \\
\text { - Maximize other's goals - pressured by the top management } \\
\text { and toy retailer, the planners of the toy supplier decided to } \\
\text { maximize the retailer's goals; }\end{array}$ \\
\hline $\begin{array}{l}\text { 4. Coordination } \\
\text { behaviour }\end{array}$ & $\begin{array}{l}\text { - No goal sharing but risk avoidance by the toy retailer } \\
\text { - Risk-taking by toy retailer - increased re-order level for all } \\
\text { products to improve fill rate and avoid lost sales }\end{array}$ \\
\hline $\begin{array}{l}\text { 5. Ordering } \\
\text { behaviour }\end{array}$ & $\begin{array}{l}\text { - Toy supplier increased order batch-size \& production plan in } \\
\text { order to increase re-order level and fill rate } \\
\text { - Toy retailer remained using just in time orders }\end{array}$ \\
\hline $\begin{array}{l}\text { 6. Subsequent } \\
\text { Flow behaviour }\end{array}$ & $\begin{array}{l}\text { - High year-end obsolete inventory at the distribution centre } \\
\text { - Less stock-out at the toy retailer }\end{array}$ \\
\hline
\end{tabular}


Revised manuscript submitted to SCM:AIJ Special Issue on Decision Making and Analysis within Supply Chains dd. 2-March-2009

Table V Decision coordination between toy supplier and retailer B

\begin{tabular}{ll}
\hline Decision \& & Interpretation and Data (based on interview, supply and \\
coordination & demand data, and meeting minutes)
\end{tabular}

\begin{tabular}{|c|c|}
\hline $\begin{array}{l}\text { 1. Observed flow } \\
\text { behaviour }\end{array}$ & $\begin{array}{l}\text { - Supply exceeded demand (over 20\% year-end stock) during } \\
\text { end of sales (after Christmas); }\end{array}$ \\
\hline 2. Mental model & $\begin{array}{l}\text { - Intuitive reasoning - both parties believed that the cause and } \\
\text { effect (of flow behaviour) were too complex to understand } \\
\text { because "it will be the same no matter what we did"; } \\
\text { - Act-sense-respond - toy retailer to order early and use price } \\
\text { mechanism to mediate demand; }\end{array}$ \\
\hline $\begin{array}{l}\text { 3. Decision- } \\
\text { making } \\
\text { behaviour }\end{array}$ & $\begin{array}{l}\text { - External attribution of root causes - "we are sometime lucky" } \\
\text { or "we just do our best, the market determines our success"; } \\
\text { - Maximize own goals - toy supplier offered discount to push } \\
\text { risk to toy retailer and toy retailer to secure inventory and } \\
\text { discounts; both being optimistic; }\end{array}$ \\
\hline $\begin{array}{l}\text { 4. Coordination } \\
\text { behaviour }\end{array}$ & $\begin{array}{l}\text { - Goal sharing - to order early with large discount; } \\
\text { - Risk-avoidance - toy retailer chosen to take inventory risk and } \\
\text { toy supplier preferred to push it to the retailer; }\end{array}$ \\
\hline $\begin{array}{l}\text { 5. Ordering } \\
\text { behaviour }\end{array}$ & $\begin{array}{l}\text { - Large batch-size and low frequency orders - toy supplier to } \\
\text { produce large batches earlier ; }\end{array}$ \\
\hline $\begin{array}{l}\text { 6. Subsequent } \\
\text { Flow behaviour }\end{array}$ & $\begin{array}{l}\text { - Supply exceeded demand - } 10 \text { products over-forecasted; } \\
\text { - High level of year-end stock - "no luck" as usual. }\end{array}$ \\
\hline
\end{tabular}


Supply Chain Management: an International Journal

Revised manuscript submitted to SCM:AIJ Special Issue on Decision Making and Analysis within Supply Chains dd. 2-March-2009

Table VI Decision coordination between toy supplier and retailer C

\begin{tabular}{|c|c|}
\hline $\begin{array}{l}\text { Decision \& } \\
\text { coordination }\end{array}$ & $\begin{array}{l}\text { Interpretation and Data (based on interview, supply and } \\
\text { demand data, and meeting minutes) }\end{array}$ \\
\hline $\begin{array}{l}\text { 1. Observed flow } \\
\text { behaviour }\end{array}$ & $\begin{array}{l}\text { - Mixed of supply exceeded demand and demand exceeded } \\
\text { supply - high level of year-end stock \& stock-out at both } \\
\text { parties; }\end{array}$ \\
\hline 2. Mental model & $\begin{array}{l}\text { - Analytical reasoning - established fixed rules to interpret flow } \\
\text { behaviour and switched to the belief that cause and effect of } \\
\text { flow behaviour being partly knowable and complex } \\
\text { (computable); } \\
\text { - Sense-analyse-respond - Established "safe" demand forecasts } \\
\text { and use point-of-sales data to correct forecasts; }\end{array}$ \\
\hline $\begin{array}{l}\text { 3. Decision- } \\
\text { making } \\
\text { behaviour }\end{array}$ & $\begin{array}{l}\text { - Internal attribution of root causes - poor flow behaviour not } \\
\text { luck-dependent by can be affected by internal decision- } \\
\text { making; } \\
\text { - Maximize goals for both - improve overall profitability for } \\
\text { both parties; }\end{array}$ \\
\hline $\begin{array}{l}\text { 4. Coordination } \\
\text { behaviour }\end{array}$ & $\begin{array}{l}\text { - Goal sharing and risk-sharing - jointly agreed on contingency } \\
\text { plan to respond to changing demand (flow behaviour) and } \\
\text { sharing of the risk of joined forecasts; }\end{array}$ \\
\hline $\begin{array}{l}\text { 5. Ordering } \\
\text { behaviour }\end{array}$ & $\begin{array}{l}\text { - Produce large batches orders earlier at "safe" quantities but } \\
\text { allocated contingency production plans; } \\
\text { - Additional orders to based on observed point-of-sales; }\end{array}$ \\
\hline $\begin{array}{l}\text { 6. Subsequent } \\
\text { Flow behaviour }\end{array}$ & $\begin{array}{l}\text { - Lower inventory level and stock-out; } \\
\text { - Lower level of year-end stock \& stock-out. }\end{array}$ \\
\hline
\end{tabular}

